\title{
Mitochondrial Production of Reactive Oxygen Species in Cortical Neurons Following Exposure to $\mathbf{N}$-Methyl-D-Aspartate
}

\author{
L. L. Dugan,, S. L. Sensi, ${ }^{1}$ L. M. T. Canzoniero,, S. D. Handran, ${ }^{1}$ S. M. Rothman, ${ }^{1}$ T.-S. Lin, ${ }^{2}$ M. P. Goldberg, \\ and D. W. Choi' \\ ${ }^{1}$ Center for the Study of Nervous System Injury and Department of Neurology, Washington University Medical \\ School, and ${ }^{2}$ Department of Chemistry, Washington University, St. Louis, Missouri 63130
}

\begin{abstract}
Increasing evidence suggests that glutamate neurotoxicity is partly mediated by reactive oxygen species, formed as a consequence of several processes, including arachidonic acid metabolism and nitric oxide production. Here we used an oxidation-sensitive indicator, dihydrorhodamine 123 , in combination with confocal microscopy, to examine the hypothesis that electron transport by neuronal mitochondria may be an important source of glutamate-induced reactive oxygen species (ROS). Exposure to NMDA, but not kainate, ionomycin, or elevated potassium stimulated oxygen radical production in cultured murine cortical neurons, demonstrated by oxidation of nonfluorescent dihydrorhodamine 123 to fluorescent rhodamine 123. Electron paramagnetic resonance spectroscopy studies using 5,5dimethyl-1-pyrroline-N-oxide (DMPO) as a radical-trapping agent, also showed production of ROS by cortical neurons after NMDA but not kainate exposure. NMDA-induced ROS production depended on extracellular $\mathrm{Ca}^{2+}$, and was not affected by inhibitors of nitric oxide synthase or arachidonic acid metabolism. The increased production of ROS was was blocked by inhibitors of mitochondrial electron transport, rotenone or antimycin, and mimicked by the electron transport uncoupler, carbonyl cyanide p-trifluoromethoxyphenylhydrazone. These data support the possibility that NMDA receptor-mediated, $\mathrm{Ca}^{2+}$-dependent uncoupling of neuronal mitochondrial electron transport may contribute to the oxidative stress initiated by glutamate exposure.
\end{abstract}

[Key words: glutamate, excitotoxicity, neurotoxicity, free radicals, mitochondria, dihydrorhodamine, oxidation, electron transport]

Tissue damage produced by reactive oxygen species, such as hydrogen peroxide, and superoxide and hydroxyl radicals, has been implicated in the pathogenesis of both acute and chronic insults to the CNS. Markers of reactive oxygen species (ROS) production have been observed in animal models of traumatic brain (Kontos and Wei, 1986) and spinal cord injury (Saunders

\footnotetext{
Received March 21, 1995; revised June 12, 1995; accepted June 14, 1995.

We thank Jui-Lin Ong, Ph.D., for technical assistance with the EPR studies. This work was supported by NIH Grants NS 30337 (D.W.C.), NS 56K (L.L.D.), NS 01543 (M.P.G.), and NS 19988 (S.M.R.).

Correspondence should be addressed to Dennis W. Choi, MD, Ph.D., Center for the Study of Nervous System Injury and Department of Neurology, Box 8111, Washington University School of Medicine, 660 South Euclid Avenue, St. Louis, MO 63110.

Copyright 다 1995 Society for Neuroscience 0270-6474/95/156377-12\$05.00/0
}

et al., 1987; Braughler and Hall, 1989), and formation of ROS and loss of endogenous antioxidants has been documented during CNS ischemia-reperfusion (Flamm et al., 1978; Chan et al., 1985; Halliwell, 1989). Further, antioxidant therapy is neuroprotective in trauma and ischemia (Saunders et al., 1987; Hall et al., 1988; Liu et al., 1989). A potential role for ROS in certain neurodegenerative disorders has also been proposed (Sinet, 1982; Beal, 1992; Cleeter et al., 1992; Halliwell, 1992; Rosen et al., 1993; but see Gurney et al., 1994).

Another pathological process that has been implicated in many of the same settings is glutamate receptor-mediated excitotoxicity. While excitotoxic and oxidative injury may occur independently, growing evidence indicates that ROS formation may also be a specific consequence of glutamate receptor activation, and may partly mediate excitotoxic neuronal damage (Choi, 1988; Coyle and Puttfarcken, 1993). Exposure of cultured cerebellar granule cells to $N$-methyl-M-aspartate (NMDA) stimulates superoxide radical formation (Lafon-Cazal et al., 1993), and antioxidants can attenuate glutamate receptor-mediated neurotoxicity (Dykens et al., 1987; Chan et al., 1990; Monyer et al., 1990; Yue et al., 1993).

Glutamate receptor activation may lead to toxic ROS formation though several cellular processes initiated by $N$-methyl-Maspartate (NMDA) receptor activation and subsequent elevation of intracellular free calcium $\left(\left[\mathrm{Ca}^{2+}\right]_{i}\right)$. Release of arachidonic acid by phospholipase $A_{2}$, initially described in ischemia (Bazan, 1970; Chan and Fishman, 1978), was subsequently linked to NMDA receptor activation (Dumuis et al., 1988). Radicals generated during NMDA-stimulated metabolism of arachidonic acid (Dumuis et al., 1988; Rose et al., 1990; Rothman et al., 1993) may add to oxidative injury. More recently, nitric oxide, a free radical gas (Garthwaite et al., 1989), has been suggested to contribute substantially to excitotoxic damage (Beckman et al., 1990; Dawson ct al., 1991; Vincent and Hopc, 1992).

Another source of ROS that may be recruited under pathological conditions is the mitochondrial electron transport chain (Flamm et al., 1978; Halliwell, 1989; Beal, 1992). Small inefficiencies in electron transport produce background levels of free radicals (Chance et al., 1979). Calcium-dependent uncoupling of electron transport from ATP production in isolated mitochondria can result in substantial free radical formation (Chacon and Acosta, 1991; Dykens, 1994). The important question whether this happens in intact neurons has been hard to address, given difficulties in detecting intracellular ROS production, and isolating a neuronal signal from that from other cell types.

The purpose of the present study was to test the specific hy- 

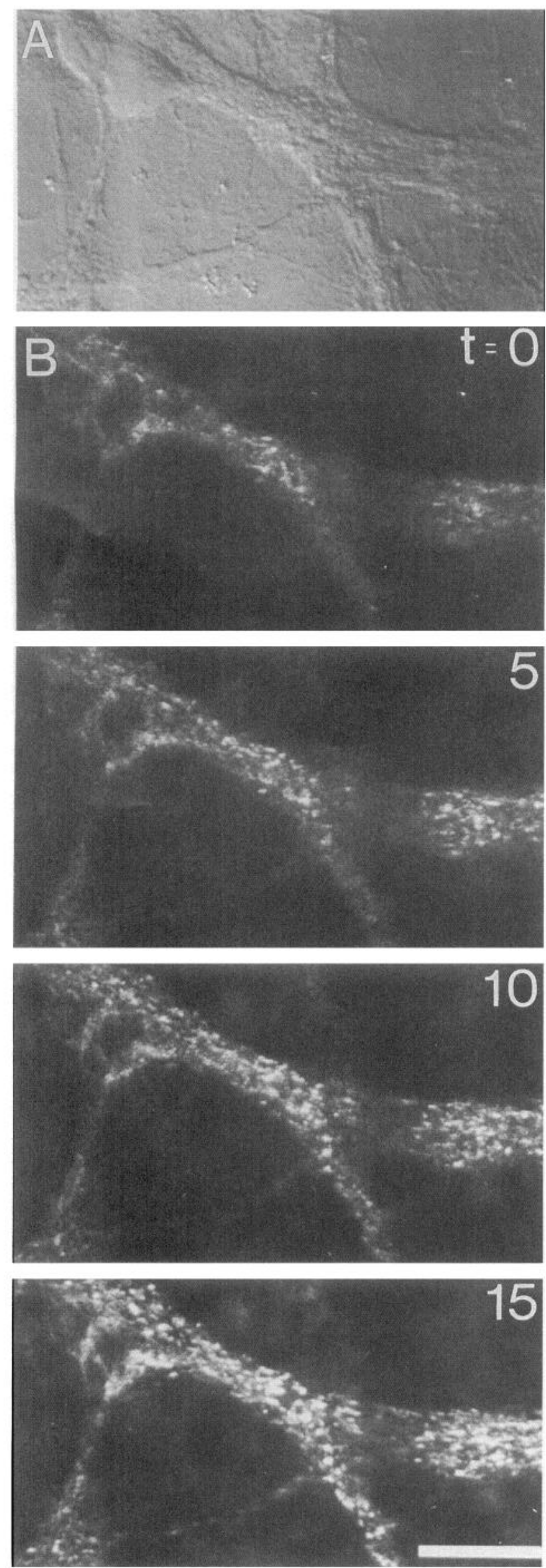
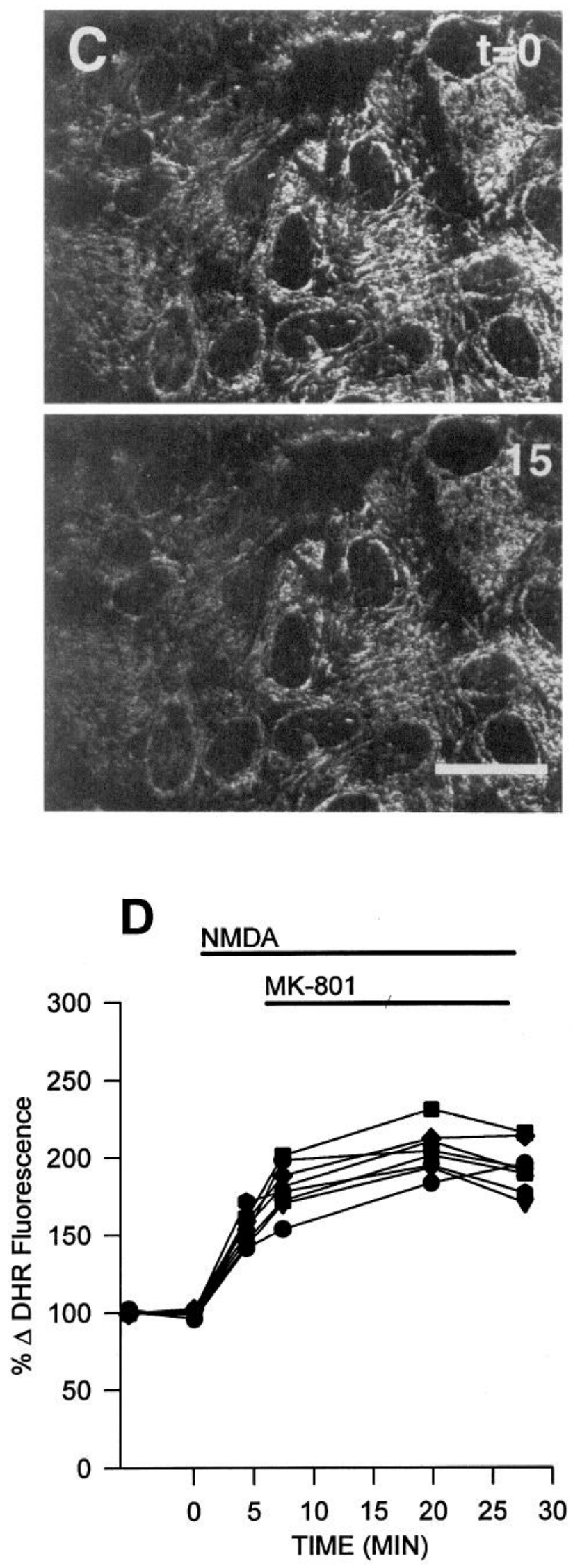
Table 1. Effects of glutamate receptor agonists, inhibitors of nitric oxide synthase and arachidonic acid metabolism, $\mathrm{Ca}^{2+}$ ionophore ionomycin, and mitochondrial toxins on dihydrorhodamine oxidation

\begin{tabular}{|c|c|c|c|c|}
\hline Cond. & Agent & $\begin{array}{l}\Delta \text { Fluorescence } \\
(\% \text { of basal })\end{array}$ & $\begin{array}{l}\text { Time } \\
\text { after } \\
\text { exposure } \\
\text { (min) }\end{array}$ & $\begin{array}{l}\text { Number } \\
\text { of cells } \\
(n)\end{array}$ \\
\hline 1 & Wash only & $76 \pm 15$ & 25 & 38 \\
\hline 2 & NMDA $100 \mu \mathrm{M}$ & $224 \pm 15^{*}$ & 25 & 237 \\
\hline 3 & $\mathrm{NMDA}+\mathrm{N}_{-\mathrm{L}-\text {-arginine } 1 \mathrm{~mm}}$ & $234 \pm 8^{*}$ & 25 & 39 \\
\hline 4 & NMDA + meclofenamate $100 \mu \mathrm{M}$ & $210 \pm 6^{*}$ & 25 & 60 \\
\hline 5 & $\mathrm{NMDA}+$ rotenone $10 \mu \mathrm{M}$ & $118 \pm 5 \dagger$ & 25 & 40 \\
\hline 6 & NMDA + antimycin A $1 \mu \mathrm{g} / \mathrm{ml}$ & $101 \pm 6 \dagger$ & 25 & 31 \\
\hline 7 & NMDA, no extracellular $\mathrm{Ca}^{2+}$ & $99 \pm 3 \dagger$ & 25 & 20 \\
\hline 8 & $\mathrm{NMDA}+\mathrm{MK}-80110 \mu \mathrm{M}$ & $98 \pm 10 \dagger$ & 25 & 21 \\
\hline 9 & Glutamate $300 \mu \mathrm{M}$ & $171 \pm 6^{*}$ & 25 & 12 \\
\hline 10 & Kainate $100 \mu \mathrm{M}+\mathrm{MK}-801$ & $85 \pm 5$ & 30 & 50 \\
\hline 11 & $\mathrm{t}-\mathrm{ACPD} 300 \mu \mathrm{M}+\mathrm{MK}-801$ & $115 \pm 2$ & 30 & 19 \\
\hline 12 & $\mathrm{KCl} 60 \mathrm{mM}+\mathrm{MK}-801$ & $105 \pm 6$ & 30 & 24 \\
\hline 13 & Ionomycin $3 \mu \mathrm{M}+\mathrm{MK}-801$ & $108 \pm 4$ & 25 & 33 \\
\hline 14 & $\begin{array}{l}\text { FCCP } 3 \mu \mathrm{M}+\mathrm{MK}-801+\mathrm{NBQX} \\
10 \mu \mathrm{M}\end{array}$ & $172 \pm 5^{*}$ & 25 & 42 \\
\hline
\end{tabular}

Conditions were as follows: (1) washed control; (2) NMDA $100 \mu \mathrm{M}$; NDMA $100 \mu \mathrm{M}$ with (3) the nitric oxide synthase inhibitor $\mathrm{N}^{\mathrm{G}}$-L-Arginine ( $1 \mathrm{mM}$, applied $15 \mathrm{~min}$ prior to $\mathrm{NMDA}$ exposure), (4) the dual lipoxygenase/ cyclooxygenase inhibitor meclofenamate $(100 \mu \mathrm{M})$, (5) the complex I mitochondrial inhibitor rotenone (10 $\mu \mathrm{M}$, added $30 \mathrm{~min}$ prior to NMDA), (6) the complex III inhibitor antimycin A ( $1 \mu \mathrm{g} / \mathrm{ml}$, added 30 min prior to NMDA); (7) $0 \mathrm{mM} \mathrm{Ca}^{2+}$ with $300 \mu \mathrm{M}$ EGTA; (8) MK-801 $10 \mu \mathrm{M}$ (as a coapplication with NMDA); (9) glutamate $300 \mu \mathrm{M}$. All subsequent conditions included $10 \mu \mathrm{M} \mathrm{MK}-801$; (10) kainate $100 \mu \mathrm{M}$, (11) the metabotropic receptor agonist tACPD $300 \mu \mathrm{M}$, (12) KCl $60 \mathrm{mM}$, (13) ionomycin $3 \mu \mathrm{M}$, and (14) the mitochondrial uncoupler FCCP (3 $\mu \mathrm{M})$, which included the AMPA/kainate receptor antagonist NBQX (2,3-dihydroxy-6-nitro-7-sulfamoyl-benzo(F)quainaoxaline $10 \mu \mathrm{M})$ in addition to MK-801. Values represent the change in fluorescence intensity as \% of basal fluorescence, mean \pm SEM; $n=$ the number of cells evaluated. Experiments involving NMDA were evaluated separately from experiments involving other agonists. ${ }^{*}, p<0.05$ vs washed control, $\uparrow, p<0.05$ vs NMDA, using repeated measures ANOVA and Bonferroni $t$ test for multiple comparisons.

pothesis that mitochondria are important sources of ROS after glutamate receptor activation in intact cortical neurons. We used confocal microscopy and the oxidation-sensitive indicator, dihydrorhodamine 123 , to measure mitochondrial ROS production. This lipophilic indicator can easily enter cells; when oxidized to the positively charged fluorescent derivative, rhodamine 123 (Henderson and Chappell, 1993; Royall and Ischoropoulos, 1993; Kooy et al., 1994), it moves to the inside-negative (about $-180 \mathrm{mV}$ ) mitochondrial environment (Johnson et al., 1980; Emaus et al., 1986).

Abstracts have appeared previously (Dugan, 1993; Dugan et al., 1994).

\section{Materials and Methods}

Cell cultures. Neocortical cell cultures were prepared from fetal (E15) Swiss-Webster mice (Simonson) as described previously (Rose et al., 1993). Cortical hemispheres were dissected away from the rest of the brain and placed in trypsin $(0.25 \%$, GIBCO) for $15 \mathrm{~min}$. The cortices were briefly centrifuged, the trypsin was removed, and the hemispheres resuspended in plating medium, which consisted of media stock (Eagle's
Minimal Essential Media minus L-glutamine, GIBCO 11430-022) with $20 \mathrm{mM}$ glucose, $26.2 \mathrm{mM} \mathrm{NaHCO}$ ), supplemented with L-glutamine ( $\mathrm{mm}$ ), $5 \%$ fetal calf serum, and $5 \%$ horse serum (Hyclone). $\Lambda \mathrm{fter}$ trituration, cell suspensions were diluted and plated onto a preexisting bed of mouse cortical astrocytes on $35 \mathrm{~mm}$ culture dishes (Mat-Tek) possessing an oval cut-out sealed by a glass coverslip. Cells were fed biweekly with growth medium (media stock with $10 \%$ horse serum, 2 mM L-glutamine), until the final feeding at day 11 or 12 in vitro, when cultures were fed with media stock supplemented with $2 \mathrm{mM} \mathrm{L-gluta-}$ mine. After 12-17 d in culture, cells were used for experiments.

Confocal microscopy. Cultures were washed into HEPES, bicarbonate-buffered balanced salt solution (HBBSS, containing, in mM, 116 $\mathrm{NaCl}, 5.4 \mathrm{KCl}, 0.8 \mathrm{MgSO}_{4}, 1.8 \mathrm{NaPO}_{4}, 12 \mathrm{HEPES}, 25 \mathrm{NaHCO}_{3}, 5.5$ D-glucose, pH 7.40 with $10 \mu \mathrm{M}$ glycine). Dihydrorhodamine 123 (Molecular Probes, Eugene, OR) stock (10 mM) was made in DMSO, and stored at $-20^{\circ} \mathrm{C}$. Dilutions of this stock were used for $3-4 \mathrm{~d}$ of experiments. Stock solutions contained a small amount $(<1 \%)$ of contaminating rhodamine 123, as measured using a Perkin-Elmer LB50 Fluorescence Spectrometer. Cells incubated with dihydrorhodamine at $37^{\circ} \mathrm{C}$ in a $5 \% \mathrm{CO}_{2}$ incubator for $30 \mathrm{~min}$ prior to microscopy.

In cells loaded with dihydrorhodamine, cellular fluorescence was imaged using a laser scanning confocal microscope (Noran Odyssey), with an argon-ion laser coupled to an inverted microscope (Nikon Diaphot)

$\leftarrow$

Figure 1. Confocal micrographs of dihydrorhodamine fluorescence during NMDA exposure. $A$, Transmitted light image of cortical neurons using differential interference contrast. $B$, Same field showing basal fluorescence (488 nm excitation, $>515 \mathrm{~nm}$ emission $\lambda$ ) following loading with 5 $\mu \mathrm{M}$ dihydrorhodamine for $30 \mathrm{~min}(t=0)$. NMDA $(100 \mu \mathrm{M})$ was then added, and images were obtained every 5 min thereafter. MK-801 $(10 \mu \mathrm{M})$ was added at the end of the $5 \mathrm{~min}$ NMDA exposure to block further receptor activation. Bar $=20 \mu \mathrm{m}$. $C$, The same field, showing no alteration of fluorescence in the glial monolayer beneath the neurons prior to $(t=0)$, or $15 \mathrm{~min}$ after addition of NMDA. $D$, Time course of the fluorescence increase during a typical NMDA experiment. Each line represents an individual neuron in the field, expressed as percentage of basal fluorescence intensity. Onset of the increased mitochondrial fluorescence varied between cultures, but the magnitude of the increase was roughly similar among most individual neurons in a given culture. 

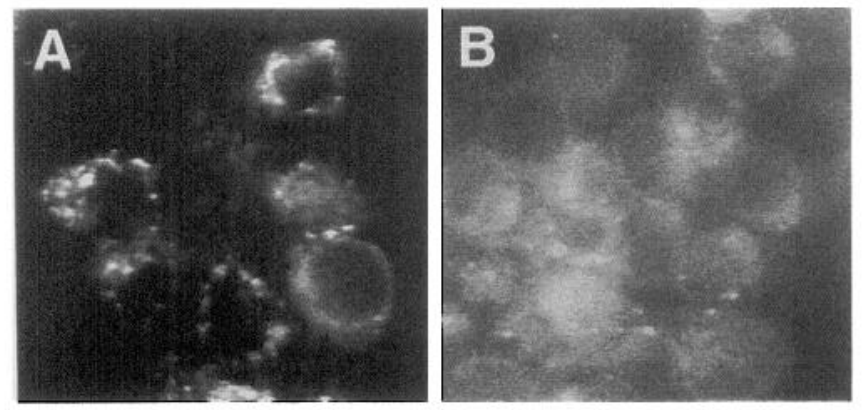

Figure 2. Confocal photomicrographs comparing punctate fluorescence observed after application of NMDA $(A)$ with the diffuse cytoplasmic fluorescence produced by addition of $\mathrm{H}_{2} \mathrm{O}_{2}(B)$. Cultures loaded with dihydrorhodamine were exposed to NMDA $100 \mu \mathrm{M}$ for $5 \mathrm{~min}$ viewed at $25 \mathrm{~min}$, or to $30 \mathrm{mM} \mathrm{H}_{2} \mathrm{O}_{2}$ for $25 \mathrm{~min}$.

equipped with a $60 \times$ oil-immersion objective (Nikon Plan Apo, N.A. 1.4). For dihydrorhodamine, excitation $\lambda$ was $488 \mathrm{~nm}$, and fluorescence was monitored at $\lambda>515 \mathrm{~nm}$. For assessment of mitochondrial membrane potential by confocal microscopy, cultures were loaded with 0.5 $\mu \mathrm{M}$ tetramethylrhodamine (Molecular Probes, excitation $\lambda=529 \mathrm{n}: \mathrm{n}$, emission $\lambda>550 \mathrm{~nm}$ ) for $30 \mathrm{~min}$. The beam was attenuated to less than $5 \%$ of maximum illumination, and laser exposure was limited to brief image acquisition intervals ( $\leq 2 \mathrm{sec}$ every $4 \mathrm{~min}$ ) using a computer-controlled shutter. These conditions for fluorescence microscopy were chosen from control experiments to minimize photo-oxidation of dihydrorhodamine, and laser settings and exposure duration were then held constant for all experiments. Frame-averaged confocal images were digitized at $512 \times 480$ or $640 \times 480$ pixels using microcomputer-based imaging software (MetaMorph, Universal Imaging). For analysis of fluorescence intensity over time, regions of interest were selected to included neuronal cytoplasm (excluding the nucleus); values reported here represent average pixel intensities within identified neurons. It was not practical to follow fluorescence intensities from individual mitochondria because of their small size and motion.

Drug application. For all experiments, cells were maintained in the original solution containing dihydrorhodamine without further media exchange; all drugs were added by diluting drug with a small aliquot $(50-100 \mu \mathrm{l})$ of medium removed from the dish. Since dihydrorhodamine will equilibrate between the intracellular and extracellular compartments, this allowed us to maintain a steady-state intracellular concentration of dihydrorhodamine throughout the experiments (Royall and Ischoropoulos, 1993). Exposure to NMDA was initiated by addition of NMDA to the culture dish, and was terminated after $5 \mathrm{~min}$ by the addition of $10 \mu \mathrm{M} \mathrm{MK}-801$. Exposure to $60 \mathrm{mM} \mathrm{KCl}, 100 \mu \mathrm{M}$ kainate, $300 \mu \mathrm{M}$ t-ACPD, $3 \mu \mathrm{M}$ ionomycin or carbonyl cyanide p-trifluoromethoxyphenylhydrazone (FCCP; $3 \mu \mathrm{M}$ ) was done in the presence of 10 $\mu \mathrm{M}$ MK-801 (and 2,3-dihydroxy-6-nitro-7-sulfamoyl-benzo(F)quinaoxaline, NBQX, $10 \mu \mathrm{M}$, in the case of FCCP). The kainate concentration chosen $(100 \mu \mathrm{M} \times 30 \mathrm{~min})$ produces near-complete loss of the total neuronal population within $24 \mathrm{hr}$ (Koh et al., 1990). A pretreatment period (30 min for rotenone and antimycin, $15 \mathrm{~min}$ for $\mathrm{N}^{\mathrm{G}}-\mathrm{L}$-Arginine) was included prior to application of NMDA for some experiments.

To determine $\mathrm{Ca}^{2+}$-dependence of dihydrorhodamine oxidation, cells were loaded with dihydrorhodamine, and cultures were then exchanged into HBBSS (containing $300 \mu \mathrm{M}$ EGTA) without $\mathrm{Ca}^{2+}$. The cells were maintained in zero $\mathrm{Ca}^{2+}$ for an additional $5 \mathrm{~min}$ after the 5 min exposure to NMDA, and then were replaced into $\mathrm{Ca}^{2+}$-containing HBBSS.

Electron paramagnetic resonance (EPR) spectroscopy. Cortical cultures were washed into HBBSS, and exposed to drugs in the presence of $100 \mathrm{~mm}$ 5,5-dimethyl-1-pyrolline-N-oxide (DMPO, as the spin-trapping agent), and diethyltriaminopentaacetic acid (DETAPAC, a chelator) at room temperature. After exposure, the sample was rapidly transferred into a quartz flat cell $(60 \times 10 \times 0.25 \mathrm{~mm})$. EPR settings on the Bruker X-band spectrometer (ER200, Bruker, Billirica, MA) were: microwave power $1.0 \mathrm{~mW}$, modulation amplitude $1 \mathrm{G}$, modulation frequency $100 \mathrm{~Hz}$, R.G. $5 \times 10^{3}$. Signal intensity was determined as the height $(\mathrm{cm})$ of the central hydroxyl radical peak on the up-field side of the midpoint.

Calcium determination. Intracellular free $\mathrm{Ca}^{2+}\left(\left[\mathrm{Ca}^{2+}\right]_{i}\right)$ was measured using fura- 2 fluorescence videomicroscopy (Grynkiewicz et al.,

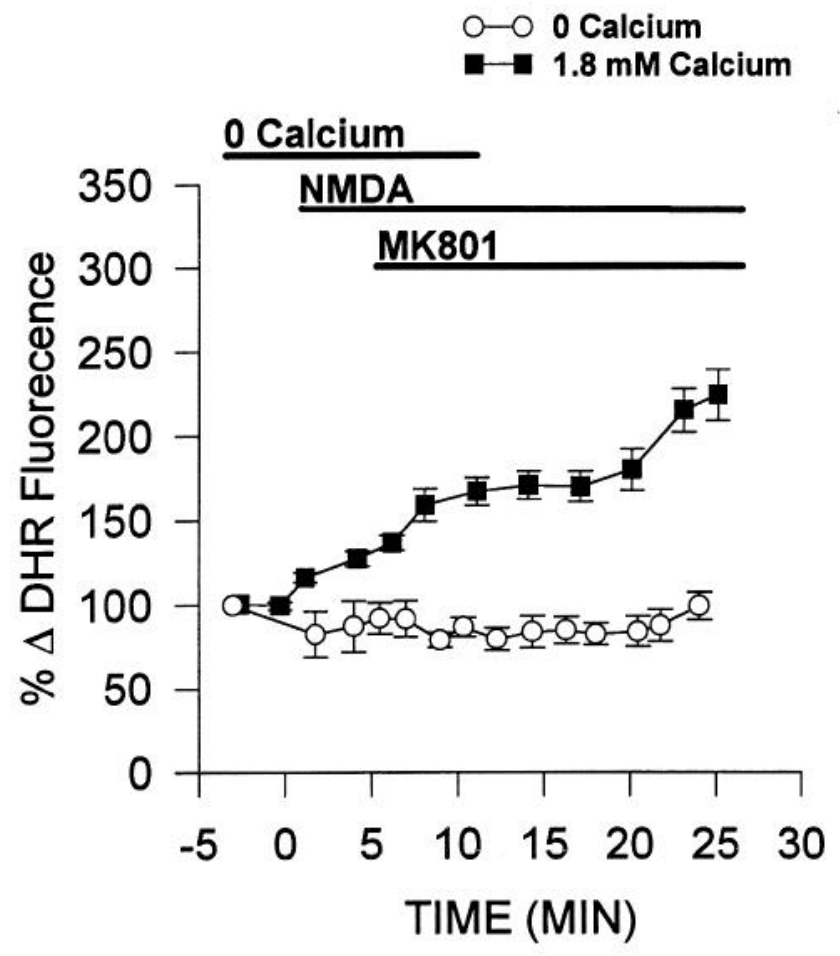

Figure 3. Mitochondrial production of $\mathrm{ROS}$ is $\mathrm{Ca}^{2+}$ dependent. Cells were exposed to NMDA in $1.8 \mathrm{mM} \mathrm{Ca}^{2+}(\square-\mathbf{\square})$, or $0 \mathrm{mM} \mathrm{Ca}^{2+}$ with $300 \mu \mathrm{M}$ EGTA $(\mathrm{O}-\mathrm{O})$, and fluoresence was measured as described in Figure $1 D$. Values represent mean \pm SEM: NMDA with $\mathrm{Ca}^{2+}, n=237$ cells, 21 experiments, NMDA without $\mathrm{Ca}^{2+}, n=20$, three experiments. The summary of statistical analyses of dihydrorhodamine data for this and subsequent figures is listed in Table 1.

1985). Neurons for intracellular $\mathrm{Ca}^{2+}$ imaging experiments were prepared as described, and experiments were performed on cultures between 12 and $17 \mathrm{~d}$ in vitro. Cells were loaded with $5 \mu \mathrm{M}$ fura-2 AM (acetyxymethyl ester) plus $0.1 \%$ Pluronic F-127 for $30 \mathrm{~min}$ at room temperature, washed, and incubated for an additional $30 \mathrm{~min}$ in HBBSS. Experiments were performed at room temperature on the stage of a Nikon Diaphot inverted microscope equipped with a $75 \mathrm{~W}$ Xenon lamp and a Nikon $40 \times, 1.3$ N.A. epifluorescence oil immersion objective. Fura-2 (Ex $\lambda=340,380 \mathrm{~nm}, \operatorname{Em} \lambda=510 \mathrm{~nm}$ ) ratio images were acquired with a CCD camera (Quantex), and digitized ( $256 \times 512$ pixels) using an Image-1 system (Universal Imaging). Calibrated $\left[\mathrm{Ca}^{2+}\right]_{i}$ values were obtained using the ratio method of Grynkiewicz et al. (1985), by determining $\mathrm{F}_{\min }$ and $\mathrm{F}_{\max }$ in situ using EGTA (10 mM) with $0 \mathrm{Ca}^{2+}$ buffer and ionomycin $(10 \mu \mathrm{M})$ for $\mathrm{F}_{\min }$, and $10 \mathrm{mM} \mathrm{Ca}{ }^{2+}$ with ionomycin $(10 \mu \mathrm{M})$ for $\mathrm{F}_{\max } . \mathrm{A} \mathrm{K}_{\mathrm{d}}$ value of $225 \mathrm{nM} \mathrm{Ca}^{2+}$ was used for Fura-2.

Replication. All experiments reported here represent at least three independent replications.

\section{Results}

\section{Dihydrorhodamine oxidation and confocal imaging}

Murine neocortical cultures were loaded with $5 \mu \mathrm{M}$ dihydrorhodamine for $30 \mathrm{~min}$ and examined for fluorescence by confocal microscopy. A low level of fluorescence was present in neurons and glia at the end of the 30 min loading period (Figs. $1 B, C, t=0)$. This background fluorescence reflected trace rhodamine 123 contamination of the dihydrorhodamine stock (see Materials and Methods), and did not change in untreated cultures over a period of at least $2 \mathrm{hr}$. Exposure of cultures to this concentration of dihydrorhodamine for $24 \mathrm{hr}$ was not toxic, and did not potentiate NMDA toxicity, as determined by morphologic assessment of cultures and LDH efflux (not shown). 

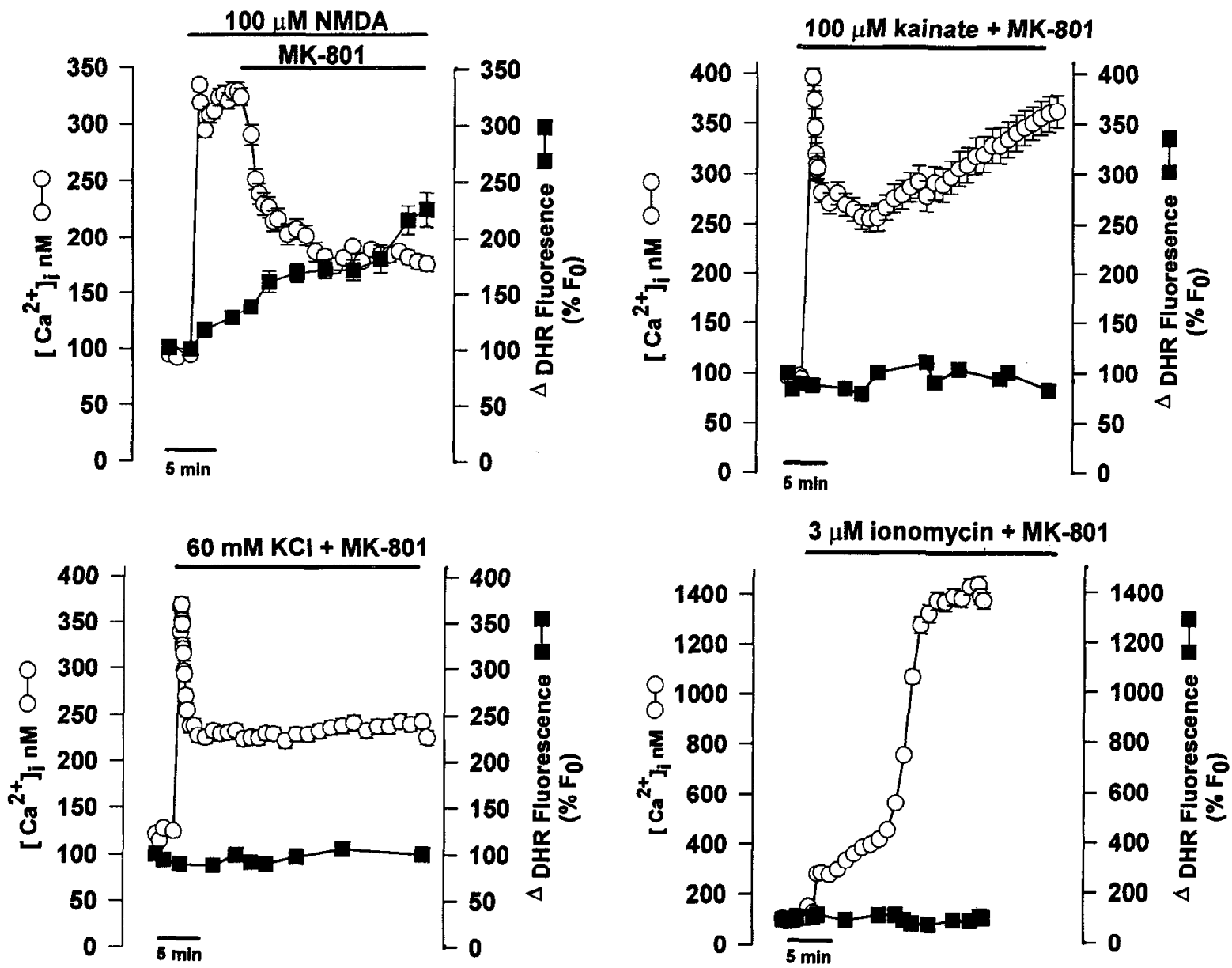

Figure 4. Exposure to NMDA $(A)$, kainate $(B)$, high potassium $(C)$, or ionomycin $(D)$ elevate intracellular $\left[\mathrm{Ca}^{2+}\right]_{i}$, but only NMDA stimulates free radical production detectable by dihydrorhodamine oxidation. Cultures exposed to various agents were imaged by Fura-2 videomicroscopy for $\left[\mathrm{Ca}^{2+}\right]_{i},(\mathrm{O})$ or by confocal microscopy for mitochondrial dihydrorhodamine oxidation $(\square) .\left[\mathrm{Ca}^{2+}\right]_{i}(\mathrm{nM})$ is shown on the left axis. Dihydrorhodamine fluorescence, which was normalized to the basal fluorescence measured prior to application of drug, is represented on the right axis as the percent of this initial fluorescence $\left(\mathrm{F}_{0}\right.$; with $\left.\mathrm{F}_{0}=100 \%\right)$. The dihydrorhodamine data for NMDA $(A)$ is the same as that presented in Figure 3 , and is included for reference. Cultures were exposed to: $A, 100 \mu \mathrm{M}$ NMDA for $5 \mathrm{~min}$, with $10 \mu \mathrm{M}$ MK-801 added after 5 min to terminate the NMDA exposure. $B, 100 \mu \mathrm{M}$ kainate coapplied with $10 \mu \mathrm{M}$ MK-801 for $30 \mathrm{~min}$. C, $60 \mathrm{mM} \mathrm{K}{ }^{+}$coapplied with $10 \mu \mathrm{M}$ MK-801 for $30 \mathrm{~min}$. D, $3 \mu \mathrm{M}$ ionomycin coapplied with $10 \mu \mathrm{M}$ MK-801 for $25 \mathrm{~min}$. $\mathrm{Ca}^{2+}$ measurements are the average of $>30$ cells per culture dish, and are representative of at least four experiments. Statistical analyses for dihydrorhodamine experiments are listed in Table 1.

Culture dishes were loaded with dihydrorhodamine and baseline fluorescence was acquired (Fig. $1 B, t=0$ ). This was followed by exposure of cells to 50-300 $\mu \mathrm{M}$ NMDA for $5 \mathrm{~min}$, then addition of $10 \mu \mathrm{M}$ MK-801 to abolish further NMDA receptor activation. Figure $1 D$ represents the dihydrorhodamine fluorescence response to $100 \mu \mathrm{M}$ NMDA exposure in a typical field of neurons. Such NMDA exposure induced a marked increase in fluorescence that was highly localized to presumptive mitochondria (Table 1, Fig. $1 B$ ), likely reflecting the oxidation of dihydrorhodamine to its fluorescent analog, rhodamine 123. Application of $300 \mu \mathrm{M}$ glutamate also increased neuronal mitochondrial fluorescence (Table 1). The glial monolayer beneath the neurons shown in Fig. $1 B$ exhibited no increase in mitochondrial fluorescence for the duration of the experimental protocol (Fig. 1C). In contrast to the localized appearance of rhodamine 123 staining after NMDA, when dihydrorhodamineloaded cultures were exposed to exogenous ROS $\left(30 \mathrm{mM} \mathrm{H}_{2} \mathrm{O}_{2}\right)$, a gradual diffuse increase in fluorescence occurred over the entire cell (Fig. 2), that required $10-15 \mathrm{~min}$ to become localized to mitochondria. Control experiments verified that sham wash or coapplication of MK-801 and NMDA failed to produce an increase in mitochondrial or cellular fluorescence, and coapplication of superoxide dismutase and catalase $(100 \mathrm{U} / \mathrm{ml}$ each $)$ to scavenge extracellular ROS failed to affect the fluorescence increase observed following NMDA.

The characteristic quenching of rhodamine 123 fluorescence as the concentration of dye in the membrane increases has been exploited for determination of mitochondrial membrane potential. Such quenching, however, might result in an underestimate of the amount of dihydrorhodamine oxidized, as the oxidation product, rhodamine 123 is taken up into mitochondria. Quenching is concentration dependent, and the amount of rhodamine 123 generated by oxidation of dihydrorhodamine in these experiments is much less the concentrations typically used for measurement of mitochondrial membrane potential. Further, 40$60 \mathrm{~min}$ after exposure to $300 \mu \mathrm{M}$ NMDA, the mitochondrial fluorescence occasionally redistributed abruptly to the cytoplasm, consistent with loss of the mitochondrial membrane potential, $\Delta \Psi$. The total cellular fluorescence, however, did not change substantially with release of rhodmaine 123 from mitochondria, indicating little quenching had occurred. No such cy- 

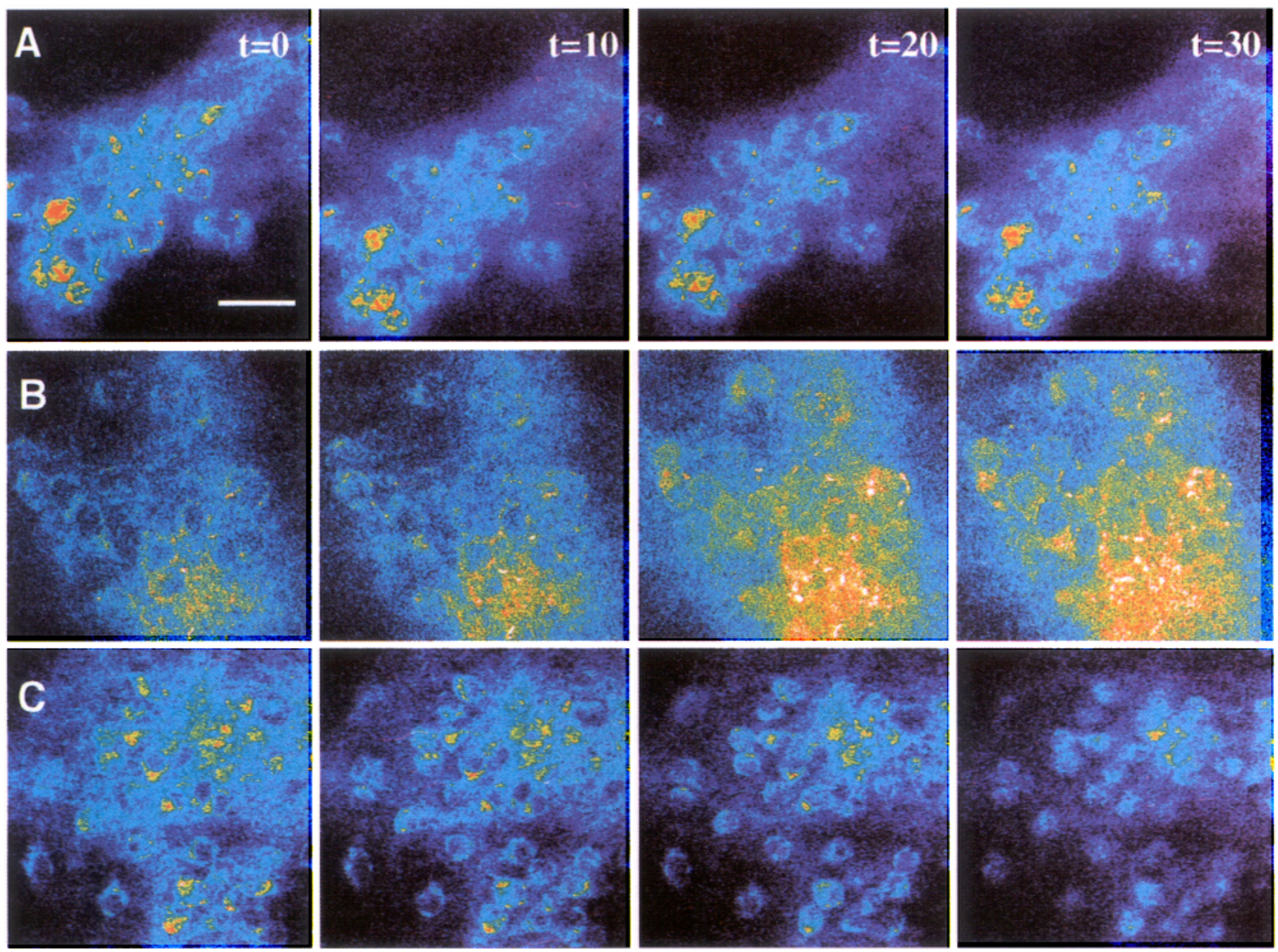

Figure 5. Confocal images of cortical cultures show oxidation of dihydrorhodamine and increased fluorescence at the indicated times (min) after exposure to $100 \mu \mathrm{M}$ NMDA $(B)$, but not after media exchange $(A)$ or exposure to $100 \mu \mathrm{M}$ kainate plus $10 \mu \mathrm{M}$ MK-801 $(C)$. Pseudocolor representation of fluoresence intensities, using arbitrary fluorescence intensity units indicated on the linear color scale. Bar $=20 \mu \mathrm{m}$.

toplasmic staining was seen after prolonged exposure to kainate sufficient to deporalize mitochondria.

Removal of external $\mathrm{Ca}^{2+}$ (in the presence of $300 \mu \mathrm{M}$ EGTA) for the duration of NMDA exposure completely abolished the oxidative conversion of dihydrorhodamine to rhodamine 123 and the resultant increase in mitochondrial fluorescence intensity (Fig. 3). In contrast to NMDA, kainate (100 $\mu \mathrm{M}), \mathrm{KCl}(60 \mathrm{~mm})$, ionomycin $(3 \mu \mathrm{M})$ (Fig. 4), and 1s, 3R-trans-1-aminocyclopentane-1,3-dicarboxylic acid (t-ACPD; $300 \mu \mathrm{M}$, a metabotropic glutamate receptor agonist (Table 1), failed to generate any fluorescent signal (Table 1, Figs. 4, 5). Each of these drugs were coapplied with $10 \mu \mathrm{M}$ MK-801 to block any secondary activation of NMDA receptors through endogenous release of glutamate. Of note, kainate, ionomycin and high $\mathrm{K}^{+}$all elicited marked increases in cytosolic free $\mathrm{Ca}^{2+},\left[\mathrm{Ca}^{2+}\right]_{i}$, comparable to that induced by NMDA (Fig. 4).

One potential explanation for the failure of kainate, ionomycin or high $\mathrm{K}^{+}$to result in enhanced rhodamine 123 fluorescence in mitochondria might be loss of the mitochondrial membrane potential, $\Delta \Psi$, resulting in dilution of mitochondrial rhodamine into the cytoplasmic and extracellular spaces. To verify that mitochondrial membrane potential remained intact for the duration of observation period used here (25-30 min), we loaded cells directly with the potentiometric dyes, tetramethylrhodamine methyl ester or rhodamine 123 itself (Johnson et al., 1980; Far- kas et al., 1989). No loss of localized mitochondrial rhodamine 123 fluorescence was observed during application of kainate for $30 \mathrm{~min}$ (Fig. 6A), ionomycin for 25 min (Fig. $6 B$ ), FCCP for 60 min (not shown), or NMDA alone (not shown). Tetramethylrhodamine gave similar results (not shown). MK-801, NBQX, NMDA, kainate, rotenone, and ionomycin showed no intrinsic fluorescence, and did not affect the rhodamine 123 fluorescence signal (not shown).

The ability of a toxic concentration of NMDA, but not kainate (Table 1, Figs. $4 C, 5$ ), to elicit production of oxygen radicals is supported by results from EPR studies using 5,5-dimethyl-1-pyrroline-N-oxide (DMPO) as a spin trapping agent. Substantial production of a characteristic $\mathrm{OH}$ EPR signal $\left(\mathrm{aN}=\mathrm{aH}_{\beta}=\right.$ $14.96 \mathrm{G}$ ) was detected after exposure of cultures to $300 \mu \mathrm{M}$ NMDA for $20 \mathrm{~min}$, but not $100 \mu \mathrm{M}$ kainate even after $2 \mathrm{hr}$ of exposure (Fig. 7A). The amount of extracellular ${ }^{\bullet} \mathrm{OH}$ detected for each experimental condition was quantified by measuring the height (in $\mathrm{cm}$ ) of the second EPR peak from each spectrum. Results are shown graphically in $7 B$.

\section{Pharmacology of ROS production}

Inhibition of two other sources of ROS generation (inhibition of nitric oxide formation by $\mathrm{N}^{\mathrm{G}}-\mathrm{L}-\mathrm{Arginine}$, or arachidonic acid metabolism by the lipoxygenase/cyclooxygenase inhibitor meclofenamate) failed to abolish the increase in mitochondrial flu- 


\section{A}
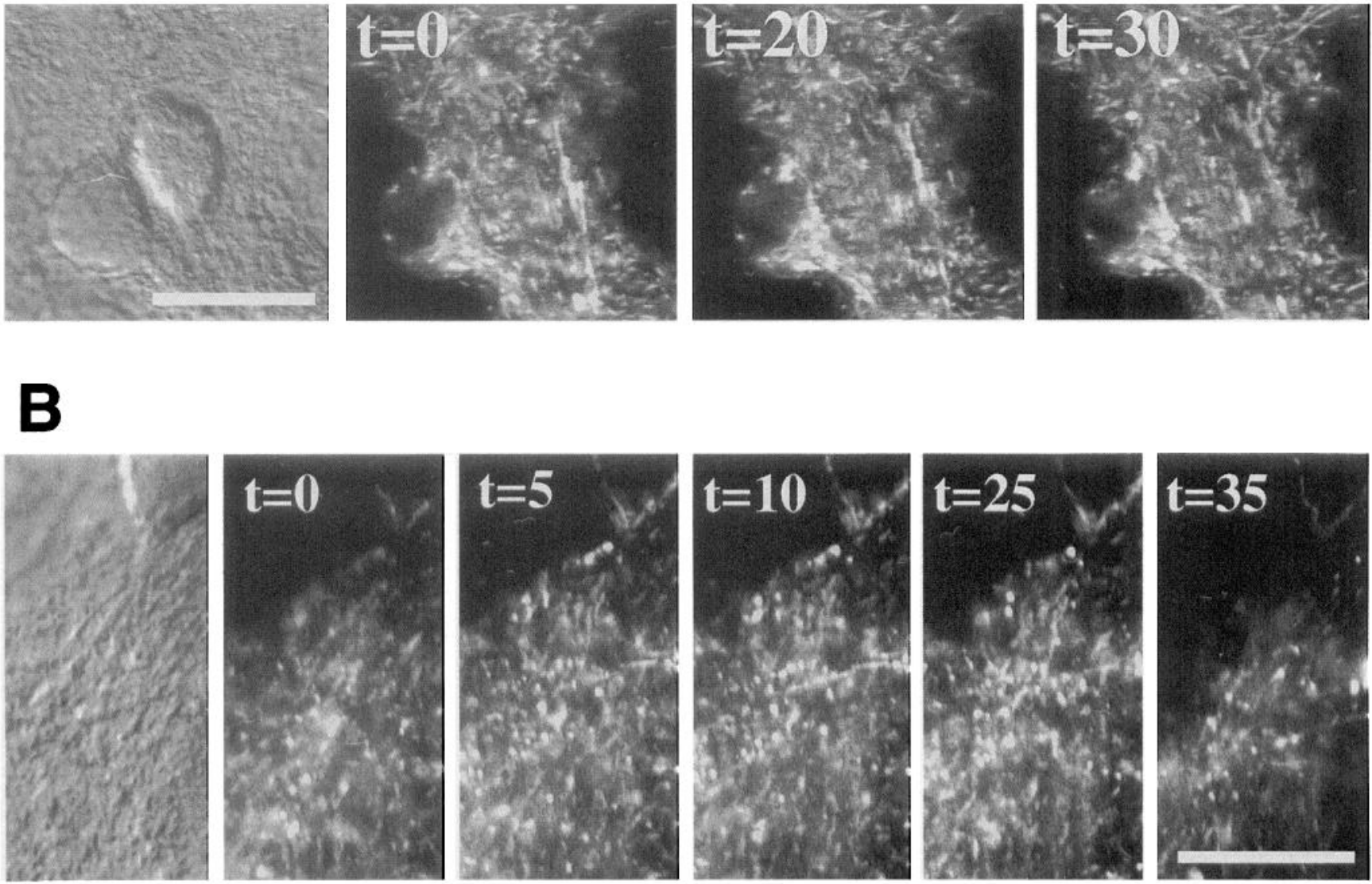

Figure 6. Neuronal mitochondrial membrane potential is maintained during exposure to kainate $(A)$, or ionomycin $(B)$. The fluorescence intensity of rhodamine $123(0.3 \mu \mathrm{M})$, an indicator of mitochondrial membrane potential, was well maintained in cells exposed to $100 \mu \mathrm{M}$ kainate for 30 min. (The small loss of fluorescence observed was comparable to that due to photobleaching in untreated controls). Ionomycin $(B, 1 \mu \mathrm{M})$ also did not decrease mitochondrial membrane potential during the relevant experimental period $(25 \mathrm{~min})$. A rapid loss of fluorescence was seen later (typically after 30-35 min). Similar results were obtained with a different potentiometric dye, tetramethylrhodamine methylester (not shown). Differential contrast photomicrographs of fields evaluated for fluorescence are included for reference. Bar $=20 \mu \mathrm{m}$.

orescence induced by NMDA receptor activation (Table 1). However, addition of the mitochondrial electron transport uncoupler, carbonyl cyanide p-trifluoromethoxyphenylhydrazone (FCCP) $(3 \mu \mathrm{M}$, added together with $10 \mu \mathrm{M}$ MK-801 and $10 \mu \mathrm{M}$ 6,7-dintroquinoxaline-2,3-dione (NBQX) to block glutamate receptors) mimicked NMDA by inducing a marked increase in mitochondrial fluorescence (Fig. 8A,B). Furthermore, inhibition of mitochondrial electron transport with Complex I or III inhibitors (rotenone, $10 \mu \mathrm{M}$ and antimycin $\mathrm{A}, 1 \mu \mathrm{g} / \mathrm{ml}$, respectively) eliminated the NMDA-induced increase in ROS formation and resulting enhanced fluorescence (Fig. 9A), without producing detectable changes in mitochondrial morphology or membrane potential, the latter assayed again by addition of rhodamine 123 itself (Fig. 9B). However, the concentrations of rotenone or antimycin A used were sufficient to inhibit mitochondrial function and to result in a shift to glycolysis and lactate production (Behrens and Choi, unpublished data).

\section{Discussion}

The present study has two major findings: (1) exposure to NMDA, but not kainate, ionomycin, t-ACPD, or high $\mathrm{K}^{+}$, induced an increase in ROS levels in murine neocortical cultures, measured within neurons by the oxidation-sensitive probe, dihy- drorhodamine, and in the bathing medium by EPR; and (2) this NMDA-induced ROS was blocked selectively by inhibitors of mitochondrial transport, but not by inhibitors of several other cellular pathways for radical generation. Both the appearance of increased fluorescence limited to mitochondria but not cytosol, and this latter pharmacology, argue for an important role of neuronal mitochondrial electron transport in producing ROS consequent to NMDA receptor activation. No evidence of glial ROS generation was detected by dihydrorhodamine in these experiments, even after kainate or high $\mathrm{K}^{+}$exposure.

Dihydrorhodamine is uncharged and rapidly loaded into cells (Royall and Ischoropoulos, 1993); it can be oxidized to rhodamine 123 by hydrogen peroxide in the presence of trace metals or peroxidase, or by peroxynitrite, but not by superoxide alone (Henderson and Chappell, 1993; Royall and Ischoropoulos, 1993; Kooy et al., 1994). Rhodamine 123 is positively charged and lipophilic, and partitions over time to mitochondria because of their large inside-negative transmembrane potential, $\Delta \Psi$. This mitochondrial localization has been used as an indicator of $\Delta \Psi$ in isolated mitochondria or intact cells (Johnson et al., 1980; Emaus et al., 1986). Oxidative conversion of dihydrorhodamine to rhodamine 123 has been used to detect ROS production by submitochondrial particles supplemented with NADH (Royall 


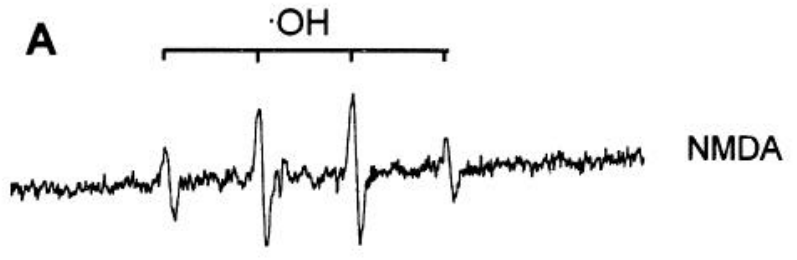

NMDA+

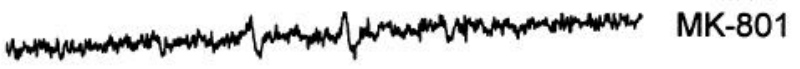

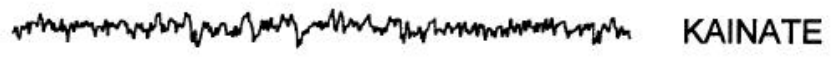

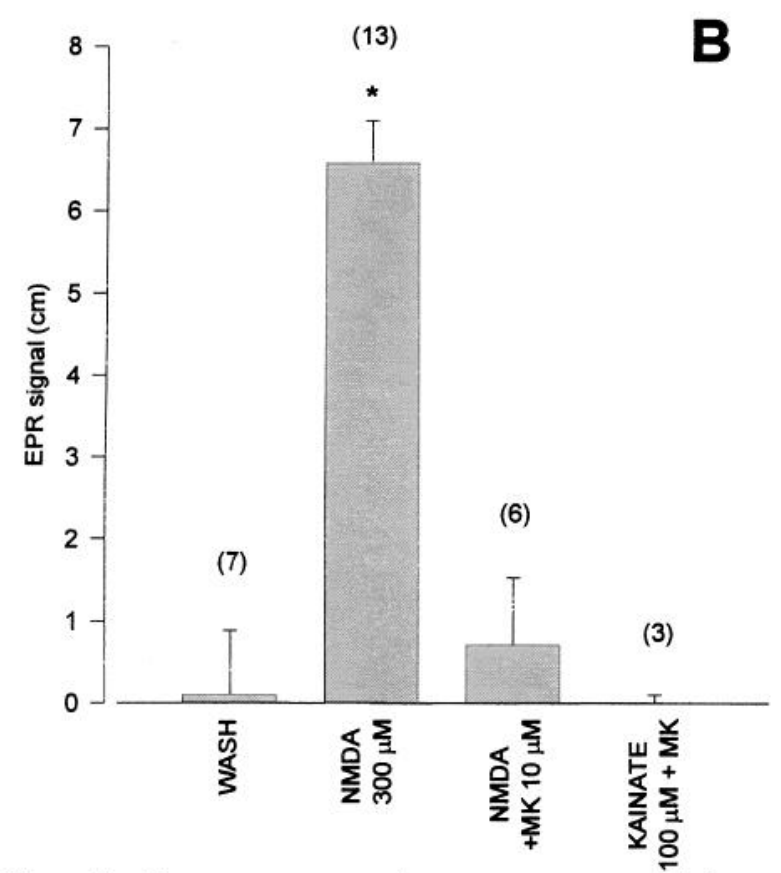

Figure 7. Electron paramagnetic resonance spectra $(A)$ from cortical cultures exposed to NMDA (300 $\mu \mathrm{M}$ for $20 \mathrm{~min}$ ), NMDA with MK$801(10 \mu \mathrm{M})$, or kainate (100 $\mu \mathrm{M}$ with MK-801, $10 \mu \mathrm{M}$, for $2 \mathrm{hr})$, using 5,5-dimethyl-1-pyrroline-N-oxide (DMPO) as a spin-trapping agent. The exposure conditions for NMDA and kainate produce roughly similar levels of neuronal injury. A characteristic ${ }^{\bullet} \mathrm{OH}$ spectrum $(1: 2: 2: 1)$, indicated by the bracket, was observed after exposure of cultures to NMDA. Coapplication of MK-801 nearly abolished the signal induced by NMDA. In contrast, cultures exposed to kainate did not exhibit evidence of ROS formation. The amount of $\bullet \mathrm{OH}$ generated by cultures exposed to NMDA or kainate was estimated by measuring the peak height of the second peak of the spectrum obtained from each culture, shown graphically in $B$. Values are mean \pm SEM, ${ }^{*} p<0.05$ versus washed control, $* * p<0.05$ versus NMDA alone, using ANOVA followed by Student-Newman-Keuls test for multiple comparisons; $n$ for each condition is shown in parentheses. and Ischoropoulos, 1993) as well as mitochondria isolated from rat cardiac myocytes (Chacon and Acosta, 1991). A valuable characteristic of rhodamine 123 is that its fluorescence is not decreased by the intracellular acidification associated with glutamate receptor activation (Sensi et al., 1993; Irwin et al., 1994). While it is possible that the mitochondrial fluorescent signal from dihydrorhodamine-loaded cells could serve as an indicator of ROS production anywhere in the cell, we showed that dihydrorohodamine-loaded cells exposed to $\mathrm{H}_{2} \mathrm{O}_{2}$ exhibited generalized fluorescence from both mitochondria and cytoplasm, not the localized mitochondrial fluorescence induced by NMDA.

Selective linkage of central neuronal NMDA receptor activation to increased levels of ROS has also been found in two other studies. Lafon-Cazal et al. (1993) found that NMDA was more effective than kainate in inducing extracellular accumulation of ROS, detected by EPR, in cerebellar granule cell cultures. Contemporaneously with our study, Reynolds and Hastings have used the cytosolic oxidation-sensitive dye, 2,7-dichlorofluorescin diacetate, to detect ROS produced by rat forebrain neurons in response to glutamate agonists (Reynolds and Hastings, 1995). Those authors found that glutamate, acting via the NMDA receptor in $\mathrm{C} \mathrm{Ca}^{2+}$-dependent manner, produced an increase in conversion of 2,7-dichlorofluorescin to the fluorescent species, 2,7dichlorofluorescein, and that this conversion was blocked by depolarizing mitochondria using FCCP. Their data are highly complementary with present data, and also led Reynolds and Hastings to the conclusion that mitochondria may be a key source of NMDA-induced ROS in central neurons. Their use of 2,7-dichlorofluorescin has the advantage of providing insight into total cytosolic ROS levels not provided here; our use of dihydrorhodamine in the present paradigm has the advantage of providing subcellular information regarding real-time mitochondrial ROS formation.

We relied on the optical sectioning ability of the confocal microscope to establish the mitochondrial localization of rhodamine 123 fluorescence, and to demonstrate that the increased signal after NMDA exposure derived strictly from neuronal mitochondria. Inhibition of a potential nonmitochondrial source of neuronal ROS, nitric oxide synthase, had no effect on NMDAinduced ROS production. A mixed lipoxygenase/cyclooxygenase inhibitor, meclofenamate, which inhibits lipoxygenase and cyclooxygenase activities in our cortical cultures (Hewett, Dugan, and Choi, unpublished observations) was also ineffective in blocking NMDA-induced mitochondrial ROS production. Other inhibitors of eicosanoid formation (e.g., nordihydroguaiaretic acid or indomethacin) were not tested here because of the intrinsic free radical scavenging properties of these compounds (Dugan and Choi, unpublished observations).

Further support for the idea that the rhodamine 123 fluorescence signal measured here reflects mitochondrial ROS generation is provided by pharmacological experiments using drugs that affect mitochondrial electron transport. FCCP, an uncoupler of electron transport, mimicked the increase in rhodamine 123 fluorescence caused by NMDA, suggesting that uncoupling of mitochondrial electron transport is sufficient to produce ROS and dihydrorhodamine oxidation. While FCCP and similar protonophores (e.g., CCCP) are frequently used to eliminate the mitochondrial proton gradient, the uncoupling produced by these protonophores is concentration dependent (Heytler, 1981; Ligeti and Lukacs, 1984; Yagi et al., 1984), so that partial uncoupling of mitochondrial electron transport can be achieved with intermediate drug concentrations. The concentration employed for 
A
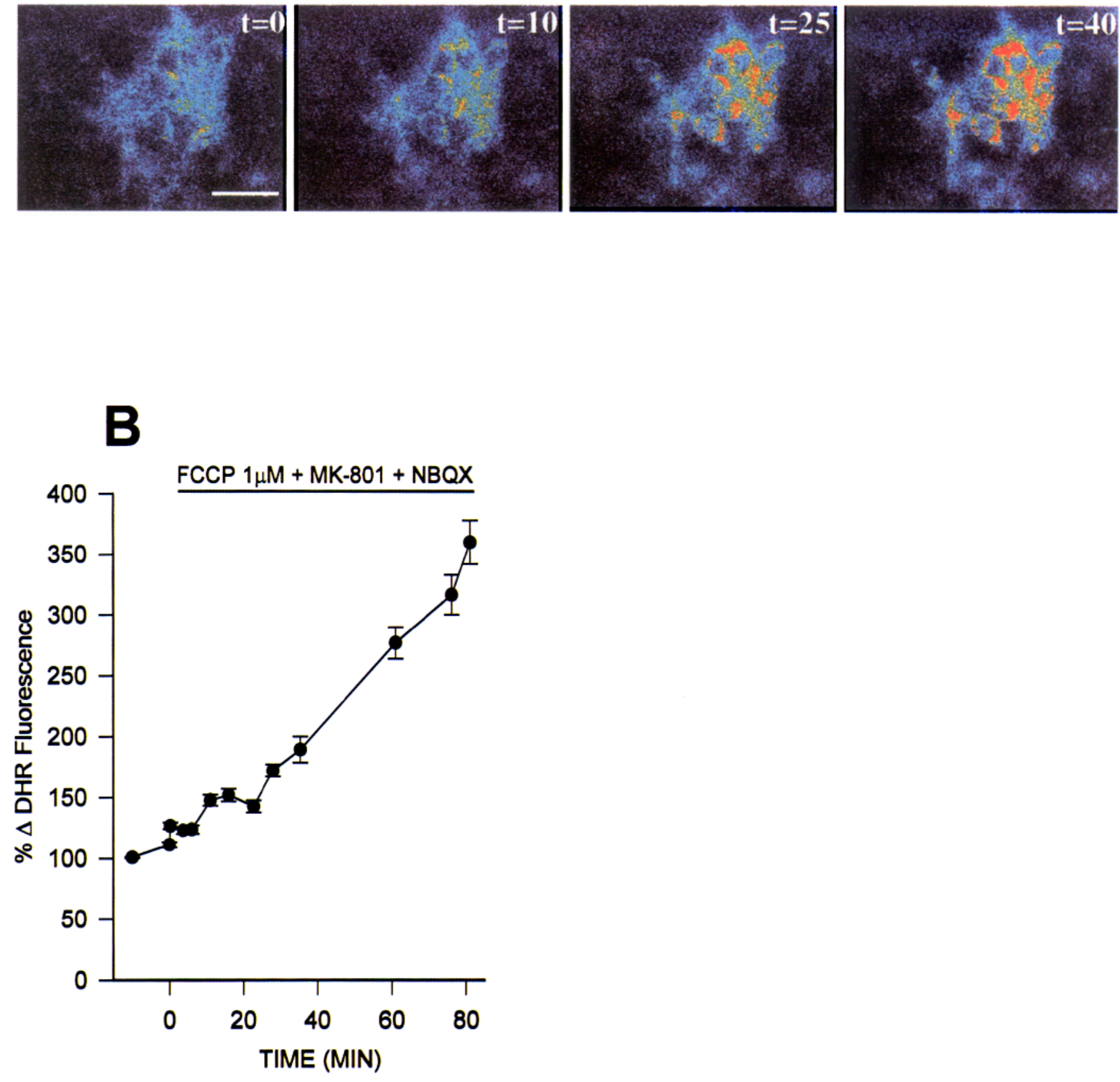

Figure 8. The mitochondrial uncoupler, FCCP, caused increased mitochondrial fluorescence (shown as a pseudocolor montage in $A$ and graphically in $B$ ), which mimicked the mitochondrial response to NMDA. Cortical cultures were exposed to $3 \mu \mathrm{M}$ FCCP in the presence of MK-801 (10 $\mu \mathrm{M}$ ) and NBQX $(10 \mu \mathrm{M})$. Curve represents the mean \pm SEM for 16 cells from one experiment, and is representative of four experiments. Statistical analyses are listed in Table 1 . Bar $=20 \mu \mathrm{m}$.

the present studies $(3 \mu \mathrm{M})$, which was chosen specifically to preserve the mitochondrial membrane potential for the duration of the present experiments, did eventually result in mitochondrial depolarization later on. It is likely that the proton gradient, after application of FCCP, is supported initially by ATP hydrolysis and proton pumping by the $\mathrm{F}_{0} \mathrm{~F}_{1}$-ATPase, i.e., by reversal of the normal ATP production by mitochondrial $\mathrm{F}_{0} \mathrm{~F}_{1}$-ATPase (Mitchell and Moyle, 1968). In other studies, micromolar concentrations of FCCP depolarized mitochondria quickly; we attribute the more delayed effect observed here to our inclusion of MK-801 and NBQX in the exposure solution (if these were omitted, rapid loss of mitochondrial fluorescence/membrane potential occurred).

We speculated that mitochondria might be a source of ROS formation induced by NMDA, as well, so we included inhibitors of electron transport during NMDA exposure to determine if dihydrorhodamine oxidation was blocked. The complex I inhibitor, rotenone, which limits entry of electrons into the respiratory chain by inhibiting NADH dehydrogenase, abolished the NMDA-induced fluorescence increase. Antimycin A, which in- 


\section{A $\quad \nabla-\nabla$ Antimycin A \\ 0 Rotenone \\ - No inhibitor}
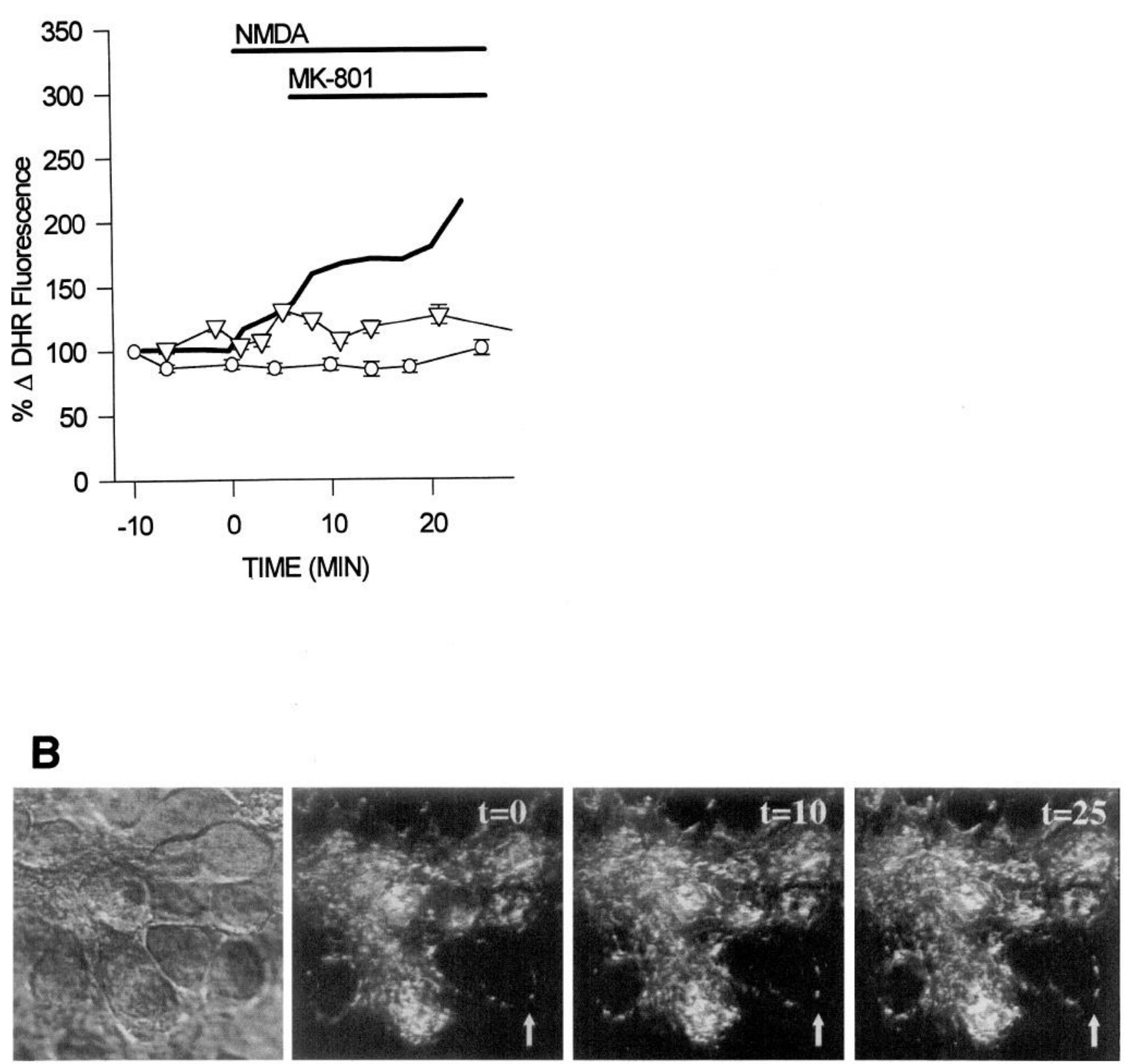

Figure 9. Mitochondrial electron transport inhibitors abolish mitochondrial ROS production after exposure to NMDA. Cells were pretreated with rotenone $(10 \mu \mathrm{M} \times 30 \mathrm{~min}, \Delta-\Delta)$, or antimycin $\mathrm{A}(1 \mathrm{mg} / \mathrm{ml} \times 30 \mathrm{~min}, \bigcirc-O)$ prior to NMDA exposure. The curve for NMDA exposure alone (from Fig. $1 D$ ) is included for reference. Mean \pm SEM for 31 cells from three experiments for antimycin A, and 40 cells from four experiments for rotenone. There was no loss of mitochondrial membrane potential for the duration of the experiment. Cells were loaded with rhodamine 123 and mitochondrial membrane potential was evaluated either as the average fluorescence intensity of the cell body, or in individual mitochondria (arrow). Higher concentrations of rotenone generally resulted in rapid loss of membrane potential after application of NMDA.

hibits electron transport through complex III, also blocked the fluorescence increase observed after NMDA exposure.

NMDA receptor activation likely induces neuronal mitochondrial ROS formation via excess $\mathrm{Ca}^{2+}$ entry and consequent cellular $\mathrm{Ca}^{2+}$ overload, as ROS formation was dependent on the presence of extracellular $\mathrm{Ca}^{2+}$ (see Reynolds and Hastings, 1995). It is noteworthy that exposure to kainate, ionomycin, or high potassium all failed to induce mitochondrial ROS formation, despite being highly effective in raising $\left[\mathrm{Ca}^{2+}\right]_{i}$. While further studies will be needed to define the basis for this difference, it is consistent with the more powerful cytotoxicity of NMDA receptor activation compared to AMPA/kainate receptor activation or depolarization (Choi, 1988; Hartley and Dubinsky, 1993; Tymianski, 1993). Although the latter are comparable to NMDA 
receptor activation in terms of inducing acute elevations in $\left[\mathrm{Ca}^{2+}\right]_{i}$ (Murphy and Miller, 1988; Michaels and Rothman, 1990; Miller, 1991), NMDA receptors induce higher levels of net $\mathrm{Ca}^{2+}$ influx into neurons (Hartley and Dubinsky, 1993), and induce a special late rise in intracellular free $\left[\mathrm{Ca}^{2+}\right]_{i}$ (Manev et al., 1989; Tymianski et al., 1993; White and Reynolds, 1995). The special ability of NMDA receptor stimulation to induce $\mathrm{Ca}^{2+}$ loading and cytotoxicity likely reflects, at least in part, the higher $\mathrm{Ca}^{2+}$ permeability of the NMDA receptor-gated channel relative to most AMPA or kainate receptor-gated channels (MacDermott et al., 1986).

However, the selective $\mathrm{Ca}^{2+}$ ionophore ionomycin failed to mimic NMDA in stimulating mitochondrial ROS generation. Although ionomycin provides a ready route for $\mathrm{Ca}^{2+}$ influx, it is conceivable that NMDA receptor-gated channels mediate higher levels of net $\mathrm{Ca}^{2+}$ entry in the experimental period studied here. NMDA receptor-gated channels permit $\mathrm{Na}^{+}$entry as well as $\mathrm{Ca}^{2+}$ entry, thus triggering additional $\mathrm{Ca}^{2+}$ influx via routes such as voltage-gated calcium channels and the $\mathrm{Na}^{+} / \mathrm{Ca}^{2+}$ exchanger (Choi, 1987; Miller, 1991; Kiedrewski et al., 1994; White and Reynolds, 1995). Indeed, activation of NMDA but not AMPA/ kainate receptors stimulates the $\mathrm{Na}^{+} / \mathrm{Ca}^{2+}$ exchanger, resulting in enhanced activity of the $\mathrm{Ca}^{2+}$-dependent phospholipase $\mathrm{A}_{2}$ in striatal neurons (Dumuis et al., 1988, 1993). Other possibilities, for example, a special spatial distribution of NMDA receptor channels on neurons relative to nonselective distribution of ionomycin, can also be considered.

NMDA receptor-induced activation of phospholipase $A_{2}$ may be a spccific mediator of mitochondrial $R O S$ production. It results in the release of free fatty acids, which uncouple mitochondrial electron transport (Wotjtczack, 1976; Hillered and Chan, 1988). Another specific link between NMDA receptor activation and mitochondrial ROS production may be enhanced cellular ATP depletion, due to NMDA receptor-mediated $\mathrm{Na}^{+}$ loading and increased membrane $\mathrm{Na}^{+}, \mathrm{K}^{+}$-ATPase activity. Cellular ATP depletion is likely to lead to increased mitochondrial respiratory activity and thus increased mitochondrial ROS production.

Sustained elevation of $\left[\mathrm{Ca}^{2+}\right]_{i}$, besides promoting mitochondrial ROS formation, may also be responsible for the late sudden loss of mitochondrial membrane potential sometimes observed 40-60 min after exposure to high concentrations of NMDA. A similar event was observed by Mattson et al. (1993), $4 \mathrm{hr}$ after exposure of hippocampal neurons to glutamate. This loss of mitochondrial membrane potential may reflect the $\mathrm{Ca}^{2+}$-dependent opening of an inner membrane pore (Gunter et al., 1994), or mitochondrial damage. A particularly vulnerable target may be complex I, the main entry point of electrons into the electron transport chain. In isolated mitochondria, complex $I$ is specifically inhibited by ROS in the presence of elevated $\mathrm{Ca}^{2+}$ (Malis and Bonventre, 1985; Dykens, 1994).

Production of ROS by neuronal mitochondrial would be cxpected to have adverse effects on many aspects of neuronal cell functions. In particular, local damage could impair mitochondrial energy production, enhancing depletion of cellular energy stores, and leading to the impairment of myriad homeostatic or protective mechanisms. In addition, mitochondrial ROS production might deplete cellular antioxidant defenses, leading to more global enhancement of oxidative stress and radical-mediated injury throughout the cell. Mitochondrial ROS production may thus be key event in the cascade of events leading to neuronal injury after excitotoxic NMDA receptor activation.

\section{References}

Bazan NG Jr (1970) Effects of ischemia and electroconvulsive shock on free fatty acid pool in the brain. Biochem Biophys Acta 218:110.

Beal MF (1992) Does impairment of energy metabolism result in excitotoxic neuronal death in neurodegenerative illness? Ann Neurol 31:119-130.

Beckman JS, Beckman TW, Chen TW, Marshall PA, Freeman BA (1990) Apparent hydroxyl radical production by peroxynitrite: implications for endothelial cell injury from nitric oxide and superoxide. Proc Natl Acad Sci USA 87:1620-1624.

Bondy SC, Lee DK (1993) Oxidative stress induced by glutamate receptor agonists. Brain Res 610:229-233.

Braughler JM, Hall ED (1989) Central nervous system trauma and stroke. I. Biochemical considerations for oxygen radical formation and lipid peroxidation. Free Radic Biol Med 6:289-301.

Chacon E, Acosta D (1991) Mitochondrial regulation of superoxide by $\mathrm{Ca}^{2+}$ : an alternate mechanism for the cardiotoxicity of doxirubicin. Toxicol Appl Pharmacol 107:117-128.

Chan PH, Fishman RA (1978) Brain edema: induction in cortical slices by polyunsaturated fatty acids. Science $201: 358-360$.

Chan PH, Longar S, Fishman RA (1987) Protective effects of liposome-entrapped superoxide dismutase on posttraumatic brain edema. Ann Neurol 21:540-547.

Chan PH, Chu L, Chen SF, Carlson EJ, Epstein C (1990) Attenuation of glutamate-induced neuronal swelling and toxicity in transgenic mice overexpressing human $\mathrm{CuZn}$-superoxide dismutase. Acta Neurochir 51:245-247.

Chance B, Sies H, Boveris A (1979) Hydroperoxide metabolism in mammalian organs. Physiol Rev 59:527-603.

Choi DW (1987) Ionic dependence of glutamate neurotoxicity. J Neurosci 7:369-379.

Choi DW (1988) Glutamate neurotoxicity and diseases of the nervous system. Neuron 1:623-634

Coyle JT, Puttfarcken P (1993) Oxidative stress, glutamate, and neurodegenerative disorders. Science 262:689-694.

Dawson VL, Dawson TM, London ED, Bredt DS, Snyder SH (1991) Nitric oxide mediates glutamate neurotoxicity in primary cortical cultures. Proc Natl Acad Sci USA 88:6368-6371.

Dugan LL (1993) Free radicals in excitotoxic neuronal injury. Abstr Second Int Symp Reactive Oxygen Species, 4.1.

Dugan LL, Sensi SL, Canzoniero LMT, Goldberg MP, Handran SD, Rothman, SM Choi, DW (1994) Imaging of mitochondrial oxygen radical production in cortical neurons exposed to NMDA. Soc Neurosci Abstr 20:1532.

Dumuis A, Sebben M, Haynes L, Pin JP, Bockaert J (1988) NMDA receptors activate the arachidonic acid cascade system in striatal neurons. Nature 336:68-70.

Dumuis A, Sebben M, Fagni L, Prezeau L, Manzoni O, Cragoe EJ, Bockaert J (1993) Stimulation by glutamate receptors of arachidonic acid release depends on the $\mathrm{Na}^{+} / \mathrm{Ca}^{2+}$ exchanger in neuronal cells. Mol Pharmacol 43:976-981.

Dykens JA (1994) Isolated cerebral and cerebellar mitochondria produce free radicals when exposed to elevated $\mathrm{Ca}^{2+}$ and $\mathrm{Na}^{+}$: implications for neurodegeneration. J Neurochem 63:584-591.

Dykens JA, Stern A, Trenkner E (1987) Mechanism of kainate toxicity to cerebellar granule neurons in vitro is analogous to reperfusion tissue injury. J Neurochem 49:1222-1228.

Emaus RK, Grunwald R, LeMasters JJ (1986) Rhodamine 123 as a probe of transmembrane potential in isolated rat-liver mitochondria: spectral and metabolic properties. Biochem Biophys Acta 850:436448.

Farkas DL, Wei M, Febbroriello P, Carson JH, Loew LM (1989) Simultaneous imaging of cell and mitochondrial membrane potentials. Biophys J 56:1053-1069.

Flamm ES, Demopoulos HB, Seligman ML, Poser RG, Ransohoff J (1978) Free radicals in cerebral ischemia. Stroke 9:445-447.

Garthwaite J, Garthwaite G, Palmer RM, Moncada S (1989) NMDA receptor activation induces nitric oxide synthesis from arginine in rat brain. Eur J Pharmacol 172:413-416.

Grynkiewicz G, Poenie M, Tsien R (1985) A new generation of $\mathrm{Ca}^{2+}$ indicators with greatly improved fluorescence properties. J Biol Chem 260:3440-3450.

Gunter TE, Gunter KK, Sheu, SS, Gavin, CE (1994) Mitochondrial 
calcium transport: physiological and pathological relevance. Am J Physiol 267:C313-C339.

Gurney ME, Pu H, Chiu AY, Dal Canto MC, Polchow CY, Alexander DD, Caliendo J, Hentati A, Kwon YW, Deng H-X, Chen W, Zhai P, Sufit RL, Siddique T (1994) Motor neuron degeneration in mice that express a human $\mathrm{Cu}, \mathrm{Zn}$ superoxide dismutase mutation. Science 264: $1772-1775$.

Hall ED, Pazara KE, Braughler JM (1988) 21-Aminosteroid lipid peroxidation inhibitor $\mathrm{U} 74006 \mathrm{~F}$ protects against cerebral ischemia in gerbils. Stroke 19:997-1002.

Halliwell B (1989) Oxidants and the central nervous system: some fundamental questions. Is oxidant damage relevant to Parkinsons disease, Alzheimers disease, traumatic injury or stroke? Acta Neurol Scand Suppl 126:23-33.

Halliwell B (1992) Reactive oxygen species and the central nervous system. J Neurochem 59:1609-1623.

Hartley Z, Dubinsky JM (1993) Changes in intracellular $\mathrm{pH}$ associated with glutamate excitotoxicity. J Neurosci 13:4690-4699.

Henderson L, Chappell JB (1993) Dihydrorhodamine 123: a fluorescent probe for superoxide generation? Eur J Biochem 217:273-280.

Heytler PG (1980) Uncouplers of oxidative phosphorylation. Pharmacol Ther 10:461-472.

Hillered L, Chan PH (1988) Role of arachidonic acid and other free fatty acids in mitochondrial dysfunction in brain ischemia. J Neurosei Res 20:451-456.

Irwin RP, Lin SZ, Long RT, Paul SM (1994) N-Methyl-M-aspartate induces a rapid, reversible, and calcium-dependent intracellular acidosis in cultured fetal rat hippocampal neurons. J Neurosci 14:13521357.

Johnson LV, Walsh ML, Chen LB (1980) Localization of mitochondria in living cells with rhodamine 123. Proc Natl Acad Sci USA 77:990994.

Kiedrowski L, Brooker G, Costa E, Wroblewski JT (1994) Glutamate impairs neuronal calcium extrusion while reducing sodium gradient. Neuron 12:295-300.

Koh JY, Goldberg MP, Hartley DM, Choi DW (1990) Non-NMDA receptor-mediated neurotocicity in cortical culture. $J$ Neurosci 10: 693-705.

Kontos HA, Wei EP (1986) Superoxide production in experimental brain injury. J Neurosurg 64:803-807.

Kooy NW, Royall JA, Ischoropoulos H, Beckman JS (1994) Peroxynitrite-mediated oxidation of dihydrorhodamine 123. Free Radic Biol Med 16:149-156.

Lafon-Cazal M, Pietri S, Culcasi M, Bockaert J (1993) NMDA-dependent superoxide production and neurotoxicity. Nature 364:535-537.

Ligeti, E, Lukacs, GL (1984) Phosphate transport, membrane potential, and movements of calcium in rat liver mitochondria. $J$ Bioenerg Biomem 16:101-113.

Liu TH, Beckman JS, Freeman BA, Hogan EL, Hsu, CY (1989) Polyethylene glycol-conjugated superoxide dismutase and catalase reduce ischemic brain injury. Am J Physiol 256:H589-93.

MacDermott AB, Mayer ML, Westbrook GL, Smith SJ, Barker JL (1986) NMDA-receptor activation increases cytoplasmic calcium concentration in cultured spinal cord neurones. Nature 321:519-522.

Malis CD Bonventre JV (1985) Mechanism for calcium potentiation of oxygen free radical injury to renal mitochondria. J Biol Chem 261: 14201-14208.

Manev H, Favaron M, Guidotti A, Costa E (1989) Delayed increase of $\mathrm{Ca}^{2+}$ influx elicited by glutamate: role in neuronal death. Mol Pharmacol 36:106-112.

Mattson MP, Zhang Y Bose S (1993) Growth factors prevent mitochondrial dysfunction, loss of calcium homeostasis, and cell injury, but not ATP depletion in hippocampal neurons deprived of glucose. Exp Neurol 121:1-13.

Michaels RL, Rothman SM (1990) Glutamate neurotoxicity in vitro: antagonist pharmacology and intracellular calcium concentrations. J Neurosci 10:283-292.

Miller R (1991) The control of neuronal calcium homeostasis. Prog Neurobiol 37:255-285.

Monyer H, Hartley DM, Choi DW (1990) 21-Aminosteroids attenuate excitotoxic neuronal injury in cortical cell cultures. Neuron 5:121126.

Murphy SN, Miller R (1988) A glutamate receptor regulates $\mathrm{Ca}^{2+}$ mobilization in hippocampal neurons. Proc Natl Acad Sci USA 85: 8737-8741.

Puttfarcken PS, Getz RL, Coyle JT (1993) Kainic acid-induced lipid peroxidation: protection with butylated hydroxytoluene and U78517F in primary cultures of cerebellar granule cells. Brain Res 624:23232.

Reynolds IJ, Hastings TG (1995) Glutamate induces the production of reactive oxygen species in cultured forebrain neurons following NMDA receptor application. J Neurosci 15:3318-3327.

Rose K, Bruno VMG, Oliker R, Choi DW (1990) Nordihydroguaiaretic acid (NDGA) attenuates slow excitatory amino acid-induced neuronal degeneration in cortical cultures. Soc Neurosci Abstr 16:288.

Rose K, Goldberg MP, Choi DW (1992) Cytotoxicity in murine neocortical cell culture. In: Methods in toxicology, Vol 1, In vitro biological systems (Tyson CA, Frazier JM, eds), pp 46-60. New York: Academic.

Rosen DR, Siddique T, Patterson D, Figlewicz DA, Sapp P, Hentati A, Donaldson D, Goto J, O'Regan JP, Deng HX, et al. (1993) Mutations in $\mathrm{Cu} / \mathrm{Zn}$ superoxide dismutase gene are associated with familial amyotrophic lateral sclerosis Nature 362:59-62.

Rothman SM, Yamada KA, Lancaster N (1993) Nordihydroguaiaretic acid attenuates NMDA neurotoxicity-action beyond the receptor. Neuropharmacology 32:1279-1288.

Royall JA, Ischoropoulos H (1993) Evaluation of $2^{\prime}, 7^{\prime}$ - dichlorofluorescin and dihydrorhodamine 123 as fluorescent probes for intracellular $\mathrm{H}_{2} \mathrm{O}_{2}$ in cultured endothelial cells. Arch Biochem Biophys 302:348-355.

Saunders RD, Dugan LL, Demediuk P, Means ED, Anderson DK, Horrocks LA (1987) Effects of methylprednisolone and the combination of alpha-tocopherol and selenium on arachidonic acid metabolism and lipid peroxidation in traumatized spinal tissue. J Neurochem 49: 24-31.

Sensi S, Canzoniero LMT, Choi DW (1993) NMDA exposure produces a long-lasting $\mathrm{Ca}^{2+}$-dependent reduction in intracellular $\mathrm{pH}$ in cortical neurons; recovery depends on extracellular bicarbonate. Soc Neurosci Abstr 19:466.

Sinet PM (1982) Metabolism of oxygen derivatives in Down's syndrome. Ann NY Acad Sci 396:83-94.

Tymianski MT, Charlton MP, Carlen, PL Tator, TH (1993) Source specificity of early calcium neurotoxicity in cultured embryonic spinal neurons. J Neurosci 13:2085-2104.

White RJ, Reynolds IJ (1995) Mitochondria and $\mathrm{Na}^{+} / \mathrm{Ca}^{2+}$ exchange buffer glutamate-induced calcium in cultured cortical neurons. J Neurosci 15:1318-1328.

Wojtczak, L (1976) Effect of long-chain fatty acids and acyl-CoA on mitochondrial permeability, transport and energy-coupling processes. J Bioenerg Biomem 8:293-311.

Vincent SR, Hope BT (1992) Neurons that say NO. Trends Neurosci 15:108-113.

Yagi, T, Matsuno-Yagi, A, Vik, SB, Hatefi, Y (1984) Modulation of the kinetics and the steady-state level of intermediates of mitochondrial coupled reactions by inhibitors and uncouplers. Biochemistry 23:1029-1036.

Yue, TL, Gu, JL, Lysko, PG, Cheng, HY, Barone, FC, Feuerstein, G (1992) Neuroprotective effects of phenyl-t-butyl-nitrone in gerbil global brain ischemia and in cultured rat cerebellar neurons. Brain Res 574:193-197. 